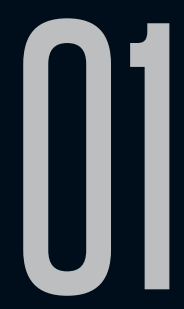

\title{
A CIÊNCIA FICÇÃO QUE NOS OLHA E A DIALÉTICA ENTRE COGNIÇÃO E ESTRANHAMENTO
}

Luana Barossi (USP)

\begin{abstract}
Recebido em 02 set 2017. Luana Barossi é Doutora em Letras (Estudos Aprovado em 03 out 2017 Comparados de Literaturas de Língua Portuguesa). No doutorado pesquisou aspectos ciência-ficcionais em narrativas contemporâneas de língua portuguesa não classificadas como ficção científica, a partir da teoria de Seo-Young Chu, e com apoio da filosofia dos afetos de Spinoza, Deleuze e Guattari e da teoria materialista do devir de Rosi Braidotti. Seus interesses de pesquisa incluem literatura fantástica, ciência ficção e teorias pós-coloniais. E-mail: luabarossi@gmail.com
\end{abstract}

Resumo: Este artigo tem como foco discutir as teorias da ciência ficção, em especial as que propõem como traço marcante desse tipo de narrativa a dialética entre cognição e estranhamento. Além disso, discutese sobre a escolha do termo ciência ficção, no lugar de ficção científica, bem como os possíveis efeitos estéticos desse tipo de narrativa no processo de leitura, efeitos responsáveis por esse "olhar" da obra para o leitor.

Palavras-chave: Ficção Científica; Estranhamento Cognitivo; Teoria Literária.

Abstract: The aim of this paper is to discuss the theories of science fiction, especially those that propose the dialectics between estrangement and 
cognition as a distinctive mark of this type of narrative. Besides that, there is a discussion on the choice for the term 'ciência ficção' instead of 'ficção científica', as well as the possible aesthetic effects of this type of narrative during the reading process, effects which are responsible for this "look" of the work to the reader. Keywords: Science Fiction; Cognitive Estrangement; Literary Theory.

Classificar não é entender. E menos ainda compreender. Como todas as classificações, as nomenclaturas são instrumentos de trabalho. Mas são instrumentos que se mostram sem utilidade quando queremos usá-los em tarefas mais sutis que a mera ordenação externa. Grande parte da crítica não passa de uma aplicação ingênua e abusiva das nomenclaturas tradicionais.

(Octavio Paz)

Antes de especificar os possíveis significados para o título, é necessário que se esclareça a escolha por "ciência ficção" no lugar do termo popularmente difundido em português "ficção científica". Não é o objetivo deste artigo renomear algo que já está nomeado, apesar de por vezes tal ocorrência ser necessária como escolha política. A seleção deste termo, no entanto, não deixa de ser política, apesar de não ser uma tentativa de renomear algo já definido, mesmo porque o que o termo definido em português (ficção científica) acaba por ser referenciado por uma tradição criada e difundida ad nauseam de forma a reproduzir um estado de coisas que se convenciona nomear como tal, mas que não é consensual.

Um dos autores brasileiros mais conhecidos que se envolveu com esta temática, André Carneiro, propôs a utilização do termo 
em inglês. Sua obra teórica sobre o tema, de 1967, é intitulada "Introdução aos estudos da science fiction". O autor questiona o termo usado em português:

Eu estava empenhado (como estou até hoje) em escrever literatura de qualidade. Quase não percebia que a temática da maioria dos meus contos se enquadrava dentro daquela maldita e absolutamente inadequada denominação de ficção cientifica. (2014, p.17)

Embora a opção feita para este artigo não condiga com a manutenção do termo em inglês, como Carneiro, consideramos que o termo science fiction perde muito de sua potência numa tradução que altera a classe gramatical das palavras que o compõem. Desta forma, a opção pelo termo "ciência ficção" no lugar do difundido "ficção científica" é uma escolha deliberada e bastante ponderada, em especial se considerarmos a definição do termo em inglês por Seo-Young Chu, autora de uma das obras teóricas contemporâneas mais importantes acerca do tema:

Significativamente, CF não é chamada nem "ficção científica", nem "ciência ficcional" expressões em que um substantivo é modificado por um adjetivo, mas "ciência ficção", uma expressão que violentamente coloca lado a lado dois substantivos heterogêneos, deixando os dois termos não modificados $^{1}$. (2010, p.157-158 - tradução nossa)

O termo em inglês corresponde a dois substantivos heterogêneos não modificados (science e fiction), de forma que

1 Por se tratar de uma definição do termo inglês, acreditamos ser importante trazer o texto original: Tellingly, SF is called neither "scientific fiction" nor "fictional science"phrases in which a noun is modified by an adjective - but "science fiction," a phrase that violently yokes together two heterogeneous nouns while leaving both terms unmodified. 
a adjetivação, do termo, adotada em português, que manteve o substantivo "ficção" e transformou o substantivo "ciência" em um adjetivo, é responsável por um esvaziamento da potência do termo science fiction. Esta é a razão da opção pelo termo ciência ficção, que se aproxima mais do termo em inglês.

Esclarecida a escolha do termo, passemos para a revisão de literatura e discussão. A ciência ficção é usualmente entendida como um gênero - ou subgênero da literatura fantástica - cujos objetos de representação são hipotéticos, normalmente relacionados ao futuro ou a alguma tecnologia possível ou imaginada que remete à ideia de especulação científica. Quando nos questionamos sobre o que faz com que uma obra seja ciência-ficcional, normalmente nos deparamos com a ideia de alguma temática recorrente nas narrativas (como robôs, descobertas tecnológicas ou aliens) ou ainda com a presença de explicações científicas para questões desenvolvidas nas narrativas. Contudo, essa é a explicação plana para o sentido do termo. Plana porque fica acima da superfície e leva mais em consideração conteúdos temáticos gerais do que o conceito propriamente dito.

Assim como a dificuldade em determinar o conceito de tempo, enfrentada por Santo Agostinho, fazendo com que o autor discorresse que há coisas que sabemos o que são quando não pensamos sobre elas, mas que quando nos perguntam o que elas são percebemos que não as conseguimos definir, o conceito de ciência ficção passa por um processo similar quando se apresenta diante de nós e parece reverter o sentido da pergunta. É como se ao olharmos para ele, o conceito nos olhasse de volta e provocasse um estranhamento rebatido: a obra de ciência ficção talvez seja aquela 
que rebate o questionamento ao olhar atento, desmantelado por esse retorno inesperado.

O cunho do termo science fiction é comumente atribuído a Hugo Gernsback, o fundador da revista Amazing Stories. Gernsback usou o termo scientifiction em 1926, para caracterizar o tipo de narrativa que sua revista publicava. Em 1929, teria sugerido a troca de scientifiction por science fiction. De acordo com Patrick Parrinder (1980), o termo permaneceu por muitos anos ligado apenas às narrativas publicadas em revistas do tipo e às antologias que republicavam essas histórias. Foi na década de 1950 que esse rótulo passou a ser utilizado para classificar obras mais longas, como romances. Gernsback propôs que Jules Verne, Edgar Allan Poe e H.G. Wells foram os precursores da ciência ficção:

Scientifiction não é uma coisa nova neste planeta. Enquanto Edgar Allan Poe foi o primeiro a conceber a ideia de uma estória científica, há suspeitas de que havia outros autores de scientifiction antes dele. Talvez eles não fossem figuras tão proeminentes na literatura e talvez eles não escrevessem o que chamamos hoje de scientifiction. (1927, p.195 tradução nossa)

O autor fornece, então, o que ele mesmo considerou como a primeira definição para seu novo termo: "por scientifiction eu quero dizer o tipo de estória de Jules Verne, H. G. Wells e Edgar Allan Poeum romance encantador entremeado com fatos científicos e visão profética" (GERNSBACK, 1927, p.3). Patrick Parrinder, no entanto, alega que Gernsback possivelmente se apropriou de definições construídas quase um século antes da sua proeminência como "fundador da ciência ficção". Parrinder remete a um texto de 1851, 
A little earnest book upon a great old subject, de William Wilson, no qual o autor já utiliza inclusive o termo Science-Fiction:

[Thomas] Campbell diz que 'Ficção na poesia não é o oposto de verdade, mas sua delicada e encantadora similitude'. Agora isso se aplica especialmente à Science-Fiction, tecida com uma agradável estória que pode ser ao mesmo tempo poética e verdadeira - circulando, assim, um conhecimento da Poética da Ciência vestida no traje de Poética da Vida. (1980, p.2 - tradução nossa)

Não podemos afirmar que Gernsback tenha tido acesso ao tratado de Wilson, mas é inegável a coincidência do nome e a similitude da definição, no que concerne ao fato de que enunciados científicos poderiam ser amalgamados a uma narrativa ficcional, tornando a narrativa próxima de uma verdade científica possível. No entanto, o tratado de Wilson, 76 anos antes do editorial da Amazing Stories, parece trazer ao campo da ciência ficção esclarecimentos mais lúcidos e menos excludentes do que os propostos por Gernsback, além de aludir a uma "poética da ciência", uma região de indiscernibilidade entre a ciência e a arte.

A definição de Wilson, apesar da data em que foi publicada, tem um teor que a torna mais atemporal que a de Gernsback, apesar de, como assinala Parrinder (1980, p.3), o fato de colocar uma "poética da ciência" como algo separado da "poética da vida" já ser antiquado em 1851, quando a revolução industrial havia atingido o ponto em que a tecnociência estava mudando o estilo de vida de forma avassaladora. Ou seja, vida e tecnologia haviam se tornado híbridas.

Independentemente de quem tenha cunhado o termo, a ciência ficção pode assumir diversas facetas, o que permitiu que 
obtivesse uma avalanche de definições. O problema é saber se chamar uma obra de ciência ficção anterior ao século XIX é uma operação anacrônica ou não. Como não sabemos exatamente a época em que o termo surgiu (talvez meados do século XIX, e não XX, como costumam acreditar os defensores de Gernsback), como saberíamos se seria anacrônico classificar uma obra, por exemplo, do século XVIII como ciência ficção? Como acreditamos que ciência ficção é antes um efeito estético/poético manifesto em determinadas circunstâncias em obras de diferentes gêneros, não consideramos anacronismo encontrar algo de ciência-ficcional em obras anteriores ao cunho do termo. Se assim fosse, não poderíamos chamar a llíada e a Odisseia de Literatura, uma vez que seu sentido contemporâneo surgiu no século XIX.

À problemática do cunho do termo, diversos autores esforçaramse em categorizá-lo de forma definitiva, mas tal tentativa acabava sendo desmantelada por outra, pois o objeto é tão fluido que pode abranger aspectos que dificilmente poderiam ser delimitados com regras fixas. Talvez essa seja uma característica daquilo que existe previamente à sua nomenclatura: a impossibilidade de enquadrar o acontecimento em definições duras.

Robert Heinlein (Apud LANDON, 2003) foi um dos autores que procurou categorizar a ciência ficção a partir de uma definição dura. Ele se propôs a delimitar, em 1947, cinco preceitos que definiriam a ciência ficção "pura" ou "íntegra". No primeiro preceito, o autor dita que as condições narrativas devem ser, em algum aspecto, diferentes do aqui-e-agora, apesar de que esta diferença deva recair somente sobre uma invenção feita no curso da história. O autor parte do pressuposto de que o real neste instante cronológico é dado e 
idêntico sob todas as perspectivas, ou que sua perspectiva é que conta. Em outras palavras, o autor adota um lócus de enunciação logocêntrico e etnocêntrico do momento corrente, criando um espaço abissal com relação a outras formas de conceber o mundo.

O segundo, terceiro e quarto preceitos de Heinlein correspondem, respectivamente, à proposição de que as novas condições devem ser uma parte essencial da história; ao fato de que o problema propriamente dito - a "trama" - deve ser um problema humano; e, por fim, esse problema humano deve ser um que tenha sido criado ou indispensavelmente afetado pelas novas condições.

Como quinto e último preceito, o autor propõe que nenhum fato estabelecido no mundo "real" deve ser violado, e, além disso, quando a história exige uma teoria contrária à teoria utilizada no presente, a nova história deve ser apresentada de forma razoavelmente plausível e deve incluir e explicar fatos estabelecidos tão satisfatoriamente quanto a que o autor achou por bem alterar. Com esse último preceito, Heinlein reafirma sua posição etno e logocêntrica, pois considera que os "fatos estabelecidos" sob sua perspectiva são necessariamente os verdadeiros e únicos neste momento.

Ademais, mesmo que o foco da narrativa recaia sobre uma teoria específica, vigente como enunciação gregária no tempo-espaço de produção da obra, então essa obra seria quiçá ciência-ficcional apenas na época do autor, pois um "fato" pode ser questionado, trazendo à luz novas teorias que por vezes desconstroem o que estava estabelecido como verdade. Ou seja, em outro momento, se a teoria utilizada por um autor hipotético (que escrevesse uma obra ciência-ficcional nos termos de Heinlein) para embasar sua 
obra for refutada, a narrativa deixaria de ser ciência-ficcional. Ela seria ciência ficcional apenas aos leitores contemporâneos à obra ou aos que se debruçassem apenas sobre o contexto de produção, fazendo uma análise dos "fatos" contemporâneos ao autor e relacionando-os à narrativa, por meio da antiga leitura aristotélica pela verossimilhança.

Phillip K. Dick, autor de Do androids dream of electric sheep?, livro que inspirou o filme Blade Runner, propõe em "My definition of Science Fiction"2 (1995) que a ciência ficção não pode ser definida como uma história ambientada no futuro, pois essa definição desconsideraria grande parte das narrativas. Ao propor que a ciência ficção não se trata de um futuro possível, nem de uma tecnologia avançada, K. Dick define então o que é necessário para que uma narrativa possa ser chamada de ciência ficção:

Temos um mundo ficcional; este é o primeiro passo: uma sociedade que não existe de fato, mas que é baseada na nossa sociedade conhecida - isto é, nossa sociedade conhecida serve como um ponto de partida para isso, a sociedade avança para fora da nossa de alguma forma, talvez ortogonalmente, como ocorre com contos ou romances de mundos alternativos. [...] [o deslocamento] deve ser suficiente para trazer à tona eventos que não poderiam ocorrer na nossa sociedade - nem em nenhuma outra sociedade, do presente ou do passado. Deve haver uma ideia coerente envolvida nesse deslocamento, isto é, o deslocamento deve ser conceitual, não simplesmente trivial ou bizarroesta é a essência da ciência ficção, o deslocamento conceitual. (1995, p.99 - tradução nossa)

2 "My Definition of Science Fiction" foi publicado pela primeira vez em Just: SF, Vol. 1, No. 1 (1981), editado por John Betancourt. 
O deslocamento conceitual proposto por K. Dick é uma das aproximações que esse tipo de narrativa faz da ciência e da filosofia. Contudo, o "olhar de volta", proposto na tentativa de definição do conceito feito anteriormente, remete à noção de leitor deslocado, de Joanna Russ (1995). O título de um artigo da autora faz emergir um conceito bastante potente: Speculations: The Subjunctivity of Science Fiction. Na primeira leitura do título, o leitor pode se indagar se não há um erro de digitação, imaginando que a palavra deveria ser "subjetividade" no lugar de "subjuntividade". Ao relacionar o título com o artigo e fazer uma leitura mais detida, torna-se claro que "subjuntividade" não está impresso no título à toa. O subjuntivo é o modo verbal que na maioria das línguas que o comportam diz respeito a possibilidades, desejos, algo que não é direto, indicado, indicativo. Quando nos perguntamos “e se...?” normalmente usamos o verbo conjugado no modo subjuntivo. No decorrer do artigo, Russ propõe que a ciência ficção é um discurso cujo assunto não existe de forma direta na perspectiva mundana. A autora ainda alega que, na ciência ficção, um protagonista deslocado é um padrão comum, ou seja, ele se encontra em um lugar estranho ou em um mundo alheio. De forma que somos (leitores) levados a um mundo estranho e nunca retornamos dele. Em outras palavras, é comum também a presença de um leitor deslocado. Esse o "olhar de volta" que o próprio conceito realiza como efeito estético ao nos questionarmos sobre seu significado.

Outros autores que elaboraram definições interessantes e bastante difundidas foram Darko Suvin (1979), Carl Freedman (2000) e Seo-young Chu (1010). Os trabalhos teóricos desses autores constituem o fio condutor da noção de ciência ficção como 
dialética entre cognição e estranhamento. Contudo, é com Chu que perceberemos o desenvolvimento da noção de ciência ficção como uma poética.

Para definir a ciência ficção, Chu primeiramente coloca algumas questões: o que significa algo se esquivar da representação?; o que faz com que alguns referentes sejam menos suscetíveis do que outros à representação?; e, finalmente, o que é preciso para um referente esquivo tornar-se disponível à representação? Na busca por esses referentes no mundo tido como conhecido, a autora estabelece sua ideia de ciência ficção como a possibilidade de representação dos referentes que não são passíveis de serem ficcionalizados por meio da representação mundana ou realista.

O que torna uma narrativa ciência-ficcional não corresponde, de acordo com Chu, aos estereótipos que para uma parcela significativa de pesquisadores e leitores definem o que torna uma narrativa ciência-ficcional ou não, a saber: robôs, androides, distopias, viagens no tempo etc. Apesar de esses motivos serem recorrentes em narrativas ciência-ficcionais, para a autora eles não são condição necessária nem suficiente para que uma obra seja assim classificada, pois são motivos presentes na narrativa e não no referente.

Outro grande salto que a autora propõe na definição do que torna uma obra ciência ficcional é uma ideia pouco intuitiva e, talvez por este motivo, também mais interessante. $\mathrm{O}$ que pode ser, em um primeiro momento, um paradigma, acaba por ser esmiuçado: a autora propõe que a ciência ficção é atributo indispensável para a mimesis (cuja definição é a citada acima, próxima da mimesis aristotélica). 
Os objetos que a ciência ficção procura representar, para Chu, são absolutamente reais, apesar de por vezes não serem palpáveis.

Um dos principais autores que dedica sua pesquisa aos Science Fiction Studies, Darko Suvin, desenvolveu quiçá um dos mais completos estudos sobre o tema, o livro Metamorphoses of Science Fiction (1979). Suvin classifica a ciência ficção como um "gênero literário cujas condições necessárias e suficientes são a presença de estranhamento e cognição e cujo principal recurso formal é um quadro imaginativo alternativo à ambientação empírica do autor" $(1979$, p.8).

Se a ciência ficção for considerada um gênero literário definidor de determinadas obras, como pode ter suas características definidas pelo processo de estranhamento e cognição, acontecimentos mais relacionados à apreciação da obra por serem diferentes de acordo com o contexto de leitura e não do que é inerente a ela? A pergunta advém do fato de as leituras de determinada obra serem sempre múltiplas, dependendo dos dispositivos de verdade, das narrativas prévias e das culturas que o leitor ou apreciador tiver previamente contato. O que é reconhecível como verdade para alguém pode não ser para outrem, provocando, no segundo caso, estranhamento. E o que é estranho para determinado leitor pode não ser, necessariamente, para outro. Retomaremos essa discussão no final do artigo.

Suvin elabora:

[A Ciência Ficção] deve ser definida como uma narrativa determinada pelo dispositivo literário hegemônico e/ou dramatis personae que (1) são radicalmente ou, pelo menos, significativamente diferentes de tempos, espaços e personagens da ficção "mimética" ou "naturalista", mas 
(2) são, todavia,- na medida em que a CF se diferencia de outros gêneros "fantásticos", isto é, conjuntos de narrativas ficcionais sem validação empírica,- simultaneamente percebidos como não impossíveis dentro das normas cognitivas (cosmológicas e antropológicas) da época do autor. [...] CF é, então, um gênero literário cujas condições necessárias e suficientes são a presença e interação de estranhamento e cognição, e cujo principal dispositivo formal é uma configuração alternativa à ambientação empírica do autor. $(1979$, p.4, 7,8)

Suvin também revigora o conceito de novum criado por Ernst Bloch (2005) em sua obra $O$ princípio esperança, para determinar o tipo de novidade necessária ao sonho diurno ou utopia concreta, o que, de acordo com Suvin, estaria presente nas narrativas de ciência ficção. Suvin adaptou o conceito de Bloch em um princípio literário que diferenciaria a ciência ficção da ficção realista.

Chu, ao invés de propor, como Suvin, que a ciência ficção corresponderia a um discurso não-mimético que alcança $o$ efeito de estranhamento cognitivo através de uma configuração imaginativa, propõe que a ciência ficção é um discurso mimético cujos objetos de representação são não-imaginários ${ }^{3} \mathrm{e}$, ainda assim, cognitivamente estranhos. O conceito-chave para a autora é, desta forma, referentes cognitivamente estranhos. No que, então, os referentes cognitivamente estranhos se diferenciam da ideia de estranhamento cognitivo de Suvin?

Para Suvin, o estranhamento, que diferencia a ciência ficção da ficção realista, é determinado por uma ambientação ou por personagens que se afastam radicalmente ou parcialmente de 3 A autora especifica que não-imaginários são os aspectos que se diferenciam da fantasia, que por sua vez se estabelece como representação estética de objetos imaginários. 
espaços e personagens da ficção "naturalista" ou "realista"; e o que diferencia a ciência ficção da fantasia ou dos contos de fadas é uma ambientação empírica não impossível se comparada à ambientação empírica do contexto de produção. Para Chu, o estranhamento está precisamente nos objetos representados e não no texto propriamente dito. O texto potencializaria o referente cognitivamente estranho através de recursos estéticos, o que a autora chama de "poética da ciência ficção".

Carl Freedman também propõe alguns deslocamentos na teoria de Suvin. Para o autor, a ciência ficção é determinada pela dialética entre estranhamento e cognição. Estranhamento, neste caso, refere-se à criação de um mundo ficcional que não toma como certas as ideias que definem nosso mundo tido como "real", propondo, desta forma, uma interrogação acerca destas certezas. Mas Freedman relaciona essa interrogação com a teoria crítica, de modo a dar materialidade à definição. A "porção crítica", de acordo com o autor, diz respeito ao que ele chama de operação cognitiva, que permite que o texto ciência-ficcional se relacione de forma racional com seu mundo imaginário, bem como este mundo imaginário realize conexões e desconexões com nosso mundo "empírico". Freedman ainda propõe uma linha gradual nessa dialética entre cognição e estranhamento: se a dialética estiver achatada na "ponta" da mera cognição, o resultado é a ficção realista ou mundana; e se a dialética estiver achatada no estranhamento, o resultado é a fantasia, que aparenta "estranhar", mas de forma teoricamente ilegítima.

O interessante na teoria de Freedman é que ela desconstrói a ideia de ciência ficção, ficção realista e fantástica como gêneros 
concisos ao estabelecer uma gradação acerca do que torna uma obra mais ou menos ciência-ficcional: é o que ele chama de tendência ciência ficção.

Assim como Chu, Freedman acredita que a ciência ficção é uma condição para a representação, e que

provavelmente não haja nenhum texto que corresponda a uma incorporação perfeita e pura de ciência ficção (quer dizer, nenhum texto no qual ciência ficção seja a única tendência genérica operativa), mas não há também texto algum no qual a tendência ciência ficção seja inteiramente ausente. De fato, pode-se argumentar que esta tendência é a condição prévia para a constituição da ficcionalidade - e mesmo da representação em si. Pois a construção de um mundo alternativo é a própria definição de ficção: devido ao caráter de representação como um processo nãotransparente que envolve necessariamente não somente semelhança mas diferença entre a representação e o "referente" dela, um grau irredutível de alteridade e estranhamento certamente ocorre mesmo no caso da ficção mais "realista" que se possa imaginar. (2000, p.20-21 tradução nossa)

A convergência entre as propostas de Suvin, Freedman e Chu está na dialética entre estranhamento e cognição. No entanto, enquanto Suvin propõe que essa dialética é o que constitui o gênero, Freedman propõe que não é um gênero, mas uma tendência genérica que está presente, em menor ou maior magnitude, em qualquer obra. Chu propõe ainda um degrau na proposta de Freedman:

Eu localizo esta dialética [entre estranhamento e cognição] não no aparato formal de um dado 
texto de CF, mas no objeto que este texto procura representar com precisão. Enquanto Freedman caracteriza a representação como um processo não-transparente que necessariamente envolve dessemelhança entre 0 referente e o texto representacional, eu caracterizo representação como um processo transparente que envolve necessariamente mais semelhança do que dessemelhança entre o referente e o texto representacional. (CHU, 2010, p.5 - tradução nossa)

Os "objetos que o texto procura representar com precisão" correspondem ao que traz ao texto a tendência ciência ficção no ponto de vista de Chu, e são o que a autora cunha como referentes cognitivamente estranhos, que, assim como propõe Freedman com relação ao estranhamento, sofrem uma gradação se imaginarmos extremos hipotéticos: objetos totalmente cognoscíveis e objetos completamente incognoscíveis. A diferença na tentativa de representação desses objetos é uma diferença hipotética em grau: de um lado, referentes completamente acessíveis à cognição; e do outro, referentes completamente estranhos. A autora explica:

Uma extremidade do espectro é povoada por objetos concretos altamente suscetíveis à compreensão e passíveis de representação. Estes incluem pincéis, folhas de carvalho, moedas, flores de maçã, amêndoas e lápis. [...] Realismo e naturalismo são extremamente capazes de representar esses objetos. A outra extremidade do espectro é ocupada por referentes quase desconhecidos, referentes que quase desafiam a linguagem e compreensão humana. Estes incluem o futuro infinitamente remoto, o passado infinitamente remoto, e o que quer que exista do outro lado da morte. Relatos 
miméticos destes referentes não existem em lugar nenhum - nem mesmo na ciência ficção. (2010, p.6 - tradução nossa)

Ao desenvolver sua conceituação espectral do estranhamento, a autora alega que a ciência ficção não corresponde a nenhuma das duas extremidades do espectro (elementos cognoscíveis de um lado, e incognoscíveis do outro), mas a rica e complexa zona central:

Nem totalmente cognoscíveis nem totalmente desconhecidos, tais referentes cognitivamente estranhos abrangem o sublime (p.ex. espaço sideral), entidades virtuais (ciberespaço), realidades imperceptíveis ao cérebro humano (a quarta dimensão), questões cujos contextos históricos ainda não foram plenamente realizados (direitos dos robôs), e eventos tão avassaladores que escapam da experiência imediata (trauma de guerra). [...] a CF se distingue por sua capacidade de realizar o trabalho imensamente complexo necessário para tornar os referentes estranhamente cognitivos disponíveis tanto para representação quanto para compreensão. (2010, p.10)

Nesta perspectiva, a ciência ficção não corresponderia, então, ao oposto da ficção realista, nem ainda a um "subgênero" da literatura fantástica, porque ela seria, como sugerem Chu e Freedman, uma condição para a representação: toda narrativa é ciência-ficcional em algum grau. Isto ocorre porque toda "realidade" é também estranhamente cognitiva em algum grau. Portanto, para Chu,

o que a maioria das pessoas chama de "realismo" o que alguns críticos chamam de "ficção mundana" - é, na verdade, uma variedade de ciência ficção "fraca" ou de baixa intensidade, aquela que exige relativamente pouca energia para realizar 
sua tarefa representacional, na medida em que seus referentes (por exemplo, bolas de softbol) são facilmente suscetíveis à representação. Por outro lado, o que a maioria das pessoas chama de science fiction ${ }^{4}$ é na verdade uma variedade de alta intensidade de realismo, que requer níveis astronômicos de energia para realizar sua tarefa representacional, na medida em que seus referentes (por exemplo, ciberespaço) intrincadamente desafiam a representação direta. (2010, p.7 - tradução nossa)

Chu ainda estabelece que o aparato formal e os referentes da arte podem mudar de época para época: "da mesma forma que o grau no qual um referente desafia a representação pode estar sujeito a flutuações, o continuum de referentes e o continuum de modos de representação podem mudar ao longo do tempo" (2010, p.8). Este desafio à representação corresponderia à porção estranha do referente. Desta forma, um "objeto" que provoca estranhamento em determinada época pode não causar em outra.

A especificação espectral de Chu, no entanto, não leva em consideração que, além do diacrônico, um deslocamento espacial explicitaria diferenças culturais. Diferentes culturas têm perspectivas distintas sobre o que são objetos concretos e o que são objetos desconhecidos.

Desta forma, proponho uma breve alteração na especificação das extremidades do espectro proposta por Chu: uma das extremidades diz respeito majoritariamente aos objetos concretos ou que fazem parte de um regime de verdade ou

4 Optamos por deixar o termo sem tradução aqui porque o termo adotado no artigo (ciência ficção) não corresponde com a forma popularizada em Português, logo, não teria sentido dizer "o que a maioria das pessoas chama de ciência ficção". 
dispositivo de saber estabelecido em dada cultura como real. $\mathrm{Na}$ outra extremidade do espectro, qualquer referente que escape à perspectiva dos regimes de verdade de determinada cultura, ou melhor, que não faça parte do grupo de elementos tidos como reais para determinada comunidade.

O que importa no momento é a relação desses conceitos elencados nos parágrafos anteriores com a variação entre o que é e o que não é considerado cognoscível, a partir de diferentes regimes de verdade. Essa variação corresponde ao que chamamos de "paralaxe do estranhamento". Saímos aqui de uma perspectiva que propõe classificar dado texto ou referente em um ponto do espectro para uma perspectiva da ciência ficção como potencial ativo no mundo do leitor, como produção de realidade. O processo de leitura ou apreciação tem o potencial de construir novos agenciamentos que se diferenciam daqueles estabelecidos como verdade no próprio mundo tido como "real". Esses agenciamentos poderiam ser chamados, em um primeiro momento, de "estranhamentos", pela diferença de potencial que produzem, no encontro com a obra, entre o mundo conhecido pelo leitor imanente e o novo regime de verdade produzido no processo de leitura.

Considero, ao contrário do que propõe Chu, que estranhamento é, como qualquer outro afeto, resultado de um agenciamento, de um encontro entre corpos em determinado percepto (ambientação). Assim, proponho a paralaxe diacrônica do estranhamento como a variação de composição de um corpo "leitor" com o corpo narrativo em determinado contexto e a composição do corpo do leitor com o corpo narrativo em outro contexto, de maneira que em um contexto o estranhamento pode 
ocorrer em certo grau e, em outro, pode ocorrer em um grau maior ou menor (ou não ocorrer).

Além da paralaxe diacrônica, o estranhamento pode flutuar relativamente às culturas em que o agenciamento ocorrer, mesmo que as culturas sejam sincrônicas. Ademais, o que pode ser estranho com relação a determinado programa de verdade (quando não faz parte dos seus agenciamentos coletivos de enunciação), não será necessariamente para outro, mesmo que esses programas de verdade coexistam em um mesmo tempo e um mesmo espaço: esta é a paralaxe sincrônica do estranhamento.

Um exemplo da paralaxe diacrônica é a leitura que um leitor hipotético faria hoje do ciberespaço em relação à leitura que outro leitor faria na década de 1980. O livro Neuromancer, de William Gibson (2008), foi inclusive a obra responsável pela propagação do termo ciberespaço, que no final da década de 1990 acabou se tornando quase sinônimo de Internet. Ou seja, apesar de a Internet ter surgido na época da guerra fria (ARPANet), foi apenas a partir de 1993 que ela abrangeu um público civil, graças à criação da World Wide Web (WWW), por Tim Berners-Lee (CERN, 2013). O ciberespaço proposto por Gibson em sua obra publicada em 1984 poderia ser considerado, então, a representação de um referente absolutamente estranho para uma parcela significativa de leitores da época: uma realidade virtual.

Após a popularização da Internet, contudo, a realidade virtual ${ }^{5}$ tornou-se parte integrante da vida de grande parte das pessoas, passando ser relacionada ao ciberespaço gibsoniano no momento de leitura, de maneira que o encontro com a obra passou a

5 Virtual aqui tem o sentido popularizado, não a conceituação bergsoniana. 
produzir mais cognição do que estranhamento, diminuindo, desta forma, o caráter de estranhamento do processo de leitura desta obra. Ou seja, uma parcela significativa de indivíduos que tenha conhecimento da existência da Internet, ao ler Neuromancer, provavelmente relacionará o ciberespaço presente na obra à Internet (mesmo que a partir de um procedimento alegórico), que é atualmente um referente cognitivamente estranho de baixa intensidade, dada a naturalidade que assumiu no cotidiano da maioria das pessoas; enquanto um indivíduo que tenha lido Neuromancer na década de 1980 provavelmente relacionaria o ciberespaço a uma ideia de realidade virtual com alto grau de estranhamento, por não ter um "objeto" popular como referente para relacionar à representação (representação, aqui, nos termos de Chu). Assim, a realidade virtual já foi um referente capaz de produzir alto grau de estranhamento cognitivo que perdeu, diacronicamente, parte de sua intensidade.

A paralaxe sincrônica do estranhamento diz respeito aos diferentes graus de estranhamento produzidos pelos encontros de leitores diferentes com uma narrativa, quando esta for lida pela perspectiva de programas de verdade de culturas distintas ou até mesmo programas de verdade concomitantes em uma mesma cultura. Tomemos como exemplo a personagem Estraven da obra $A$ mão esquerda da escuridão, de Ursula K. Le Guin (2008). Estraven é ume $^{6}$ habitante do planeta Gethen que não tem sexo biológico nem gênero definidos. Há diversas possibilidades de leitura para Estraven, como para qualquer elemento da obra, mas suponhamos uma leitura

6 Em decorrência da ausência de definição de sexo e gênero da personagem, o artigo indefinido não pode ser colocado no masculino ou no feminino. Utilizei aqui "ume" como uma forma de adequar a linguagem à indeterminação de gênero. 
dessa personagem relacionando-a a um referente do "mundo real": um indivíduo intersexual. Agora suponhamos que duas pessoas diferentes leiam a obra de Le Guin ao mesmo tempo: a primeira nunca pensou na intersexualidade, nunca conviveu com um indivíduo intersexual e sua cultura é baseada na ideia binária de sexo e gênero. A segunda tem um programa de verdade mais maleável com relação a essas questões. Para o primeiro indivíduo, a intersexualidade é um referente cognitivamente estranho de alta intensidade.

Mesmo se Estraven não fizesse parte de uma cultura extraterrestre, mesmo se fosse humano, o leitor provavelmente ainda obteria esse efeito de estranhamento ao se compor com a obra, pois a intersexualidade não faz parte dos seus regimes de verdade, ele ignora isso como possibilidade antes desta experiência de leitura. Isso se passa porque sua imaginação constituinte relacionada a sexo e gênero são fixados na ideia de masculino/feminino; homem/mulher.

Além do sexo como um "dado biológico", como considerado "natural" pelos agenciamentos de poder de diversos espaços, se pensarmos em gênero como um processo de subjetivação, teríamos um grau ainda mais elevado de estranhamento por parte do primeiro leitor hipotético. Isso porque o binarismo de gênero é tão incrustado nos regimes de verdade (corroborados inclusive por dispositivos de poder, como a medicina), que um indivíduo não-binário ou genderqueer é completamente incompreendido ou ainda territorializado pelos dispositivos psicanalíticos como "disfórico". A classificação da transexualidade como um transtorno da identidade sexual é um fator de marginalização daqueles que não se identificam com o sexo que lhes foi designado ao nascer e com a estrutura social estabelecida como "normal". 
Esse processo de estranhamento no que concerne a gênero e a sexo (e, em outros casos, também à sexualidade) tem uma genealogia bem definida por Michel Foucault em $A$ história da sexualidade. Para formar um dispositivo de poder, essas definições foram construídas de forma a parecer uma referência segura e fixa, como se fossem baseadas apenas em dados biológicos e naturais. Mas nem a partir dos dados biológicos a concepção binária de sexo e gênero se mantêm, pois o que falar dos indivíduos que não correspondem a essas características "fisiológicas" nem mesmo ao nascimento, como é o caso de intersexuais?

Para manter este dispositivo que estabelece historicamente uma série de relações de poder (por exemplo, papéis sociais masculinos e papéis sociais femininos, responsáveis pela naturalização da estrutura social patriarcal), os indivíduos intersexuais tiveram sua existência podada pela patologização da sua diferença. Logo, se não for homem nem mulher numa sociedade construída com base em valores binários, não é ninguém. Ou melhor, é um indivíduo portador de uma síndrome (no caso dos intersexuais) ou de um transtorno mental (no caso dos transexuais), que passa a ser tratado como um doente e, no caso dos primeiros, normalmente criados a partir dos estereótipos formatados genealogicamente para um dos gêneros.

No caso da obra de Le Guin, a existência do intersexual, ainda que na perspectiva de um narrador "terráqueo" (Genly $\mathrm{Ai}$ ), pode ser um fator transformador do mundo do leitor que tem como verdade a construção binária homem/mulher. Esse estranhamento não é causado pelo fato de Estraven ser uma personagem "de outro planeta", como um leitor ou crítico de ciência ficção poderia sugerir, mas pelo estremecimento nos regimes de verdade do leitor 
(que pareciam tão fixos) provocado pela existência intersexual de Estraven. A obra olha para o leitor quando o leitor olha para ela.

Para compreender como o referente cognitivamente estranho não está "preso" ao que é usualmente classificado como ciência ficção (no caso em questão, extraterrestres), tomemos como exemplo outra personagem, de uma obra fílmica muito mais "presa" ao mundo que chamamos real. Dirigido por Lucía Puenzo (2007), o filme de produção argentina/espanhola/francesa $X X Y$ apresenta a personagem Alex, uma pessoa que nasceu com o que, de acordo com a medicina tradicional, se chamaria de anomalia ou síndrome. Não se especifica se ela é "portadora da síndrome de Klinefelter", apesar do nome do filme assim sugerir. Mas isso não importa para o contexto deste artigo porque a intenção aqui é precisamente considerar a personagem além dos dados genéticos que a definiriam a partir de uma ciência supostamente isenta de relações de poder. O que importa aqui é que Alex não tem sexo definido, tem características biológicas tanto do que chamamos convencionalmente de sexo feminino quanto do que chamamos de sexo masculino. No entanto, é criada como mulher, dentro dos estereótipos de gênero que se pressupõem culturalmente para o gênero. Para tanto, ela tem que se submeter desde bebê a um tratamento radical com hormônios para suprimir suas características masculinas. A escolha dos pais é baseada na intenção de evitar o sofrimento da criança (que não é homem nem mulher) em uma cultura que se fixa em um programa de verdade binário no que diz respeito a gênero e sexo (e que, na maioria das vezes, utiliza sexo e gênero como sinônimos). No entanto, quando Alex chega à adolescência, começa a questionar a escolha que os pais fizeram. 
Passa a se indagar sobre qual o problema de ser intersexual, por que isso é tratado como uma síndrome? Até que ela decide parar de fazer tratamento e viver sua singularidade.

Quando um espectador/leitor, que desconhece a intersexualidade como possibilidade de existência por estar inicialmente fixado nos regimes de verdade binários, se depara com a personagem Alex, que é mais "realista" do que a extraterrestre Estraven, pode perceber esse referente, no agenciamento, quase na mesma intensidade do que esta de referente estranhamente cognitivo.

Ou seja, o estranhamento não vem de invenções fantásticas ou imaginárias, necessariamente. Pode se manifestar em alto grau até em uma obra considerada "realista". A paralaxe sincrônica do estranhamento, neste caso, se daria no encontro de um segundo leitor/espectador hipotético, com a obra de Le Guin ou com o filme de Puenzo. Imaginemos que este indivíduo tenha uma perspectiva diferente com relação a sexo e gênero, que entenda essas questões de forma mais fluida, menos estereotipada e menos binária, bem como questione a ideia de que qualquer característica que se diferencia de um padrão determinado socialmente como "normal" seja considerada anomalia. Para este indivíduo, a singularidade de Estraven e de Alex em suas indefinições de sexo e gênero é um dado corriqueiro, faz parte dos seus regimes de verdade ou ao menos não é interditada como possibilidade de existência. Desta forma, o efeito do encontro com as obras, que era de estranhamento em alta intensidade no primeiro indivíduo, será de baixa intensidade no segundo. 
Logo, o estranhamento no processo de apreciação de uma obra é circunstancial de forma diacrônica ou sincrônica, além de se manifestar inclusive no encontro com obras que são normalmente classificadas como realistas.

Torna-se possível, assim, apreender distintas possibilidades de leitura de uma mesma obra, observando os diferentes graus em que os possíveis referentes são cognitivamente estranhos ou ainda a recusa de um referente, no caso de uma leitura literal. Então, mesmo se pensarmos em referentes mais "reais", temos que considerar que esses referentes podem ter seu caráter de "real" flutuante de acordo com distintos regimes de verdade; bem como considerar que uma mesma obra pode dizer respeito a mais de um referente, dependendo de leituras distintas em decorrência da época em que a obra foi apreciada ou do contexto cultural de recepção da obra (os regimes de verdade que fazem parte do background do leitor). Destarte, proponho que o estranhamento não é inerente necessariamente à obra propriamente dita, mas se dá no encontro do corpo leitor com o corpo narrativo.

Esse embate não é unilateral no caso da ciência ficção. Não é apenas o leitor que olha para a obra, mas a obra retorna esse olhar. O que olha para nós, nessa leitura, é o que nos torna leitores deslocados, como na proposta de Joanna Russ. Somos levados a um mundo estranho e nunca retornamos dele porque percebemos que aquela obra nos enxergou, talvez mais do que a tenhamos enxergado.

Para entender essa dimensão da ciência ficção que nos olha, pensemos nos dois exemplos que demos de obras classificadas como ciência ficção: a primeira, Neuromancer, trata de um espaço 
outro; enquanto a segunda, $A$ mão esquerda da escuridão, trata de um corpo outro. O ponto em comum entre elas é um aspecto de alteridade, o que é um ritornelo da noção de deslocamento sugerida por Russ. Esse deslocamento é evidenciado também em recursos estéticos comuns a uma obra usualmente classificada como ficção científica, resultando no que Chu (2010) chamou de poética da ciência ficção. A palavra poética é empregada pela autora em decorrência da aproximação que ela faz entre o discurso ciência-ficcional e o discurso lírico em uma série de elementos. As qualidades, tanto sozinhas, quanto em combinação, que costumam compor uma obra de ciência ficção tendem a coincidir, em alguns pontos, com recursos líricos frequentes na poesia. Essa coincidência se dá pela intensidade trazida pela linguagem figurativa. Os textos ciência-ficcionais comumente trazem uma espécie de literalização de figuras poéticas que fazem com que o texto transcenda a dicotomia entre o literal e o figurativo.

Um desses elementos de aproximação, que se relaciona com a questão da personagem deslocada e com o espaço deslocado, é a recorrência de solilóquios em textos usualmente classificados como ciência ficção. Embora nem sempre presentes, os solilóquios são comuns nessas obras e, em geral, são desenvolvidos por uma personagem deslocada. Tomemos como exemplo a personagem June, de The handmaid's tale (ATWOOD, 1985). June (Offred) é narradora quase na totalidade da obra, que é uma espécie de narrativa emoldurada, como o Decameron de Bocaccio ou os Contos da Cantuária. O que diferencia a estrutura da obra de Atwood dessas últimas é que, ao contrário de Chaucer e Boccacio, a narrativa central emoldura apenas uma história. Outra diferença é que só sabemos 
que se trata de uma narrativa emoldurada ao final da obra, no epílogo intitulado "Notas Históricas", que trata da narrativa com um distanciamento temporal. Enquanto June narra a história, é usualmente em forma de solilóquio. A obra, comumente classificada como distopia, passa-se em Gilead, uma sociedade religiosa com papéis muito bem definidos para as mulheres. As handmaids (aias, na tradução ao português) são responsáveis pela reprodução, em um mundo onde grande parte da população se tornou estéril. June é uma aia, que é nomeada Offred ao ser designada ao seu "dono", o comandante Frederick Waterford. As aias recebem os primeiros nomes dos seus comandantes, que são aglutinados na partícula "Of" (de), indicando pertencimento. Além disso, as mulheres (aias ou não) são proibidas de ler e de se reunir fora dos rituais convencionais. June retoma lembranças de antes do golpe que instituiu o regime de Gilead, contrapondo frequentemente ao seu momento atual e interdito à sua vida livre antes do golpe. A sociedade distópica de Gilead, por meio dos solilóquios de June, quando confrontada pelo leitor atento, retorna esse olhar. Lançando mão de uma hipálage, a sociedade de Gilead lança ao leitor um olhar irônico, um olhar zombeteiro de quem mostra, de maneira potencializada, um espelho.

Este olhar, por vezes incrível, por vezes aterrorizante, emana do "eu" ciência-ficcional, quase um eu lírico que nos olha do outro lado, por aquele horizonte tênue que separa a experiência empírica do espaço diegético. Esse "eu" e esse espaço que nos alcança com seu olhar, com a potencialização do nosso terror, dos nossos piores pesadelos, provocam em nós o efeito estético do deslocamento, como se fôssemos transportados para outra dimensão, que, apesar de outra, é a nossa mesmo, apenas conseguimos olhá-la pelo viés 
daquele personagem deslocado, que assim como June e Gilead, potencializa o que há de melhor e de pior em nós mesmos.

\section{REFERÊNCIAS}

ATWOOD, Margaret (1985). The Handmaid's Tale. London: Virago Press.

BLOCH, Ernst (2005). O Princípio Esperança (1). Rio de Janeiro: Contraponto.

CARNEIRO, André (2015). Entrevista por José Carlos Neves. Revista Somnium. (111) In http://www.clfc.com.br/Somnium111.pdf Acesso em 30.Jul.2017.

CERN (2013). The birth of the web. In http://home.web.cern.ch/topics/birth-web Acesso em 30.Jul.2017.

CHU, Seo-Young (2010). Do metaphors dream of literal sleep? A science-fictional theory of representation. Cambridge: Harvard University Press.

DICK, Philip K. (1995). The Shifting Realities of Philip K. Dick: Selected Literary and Philosophical Writings. Lawrence Sutin (Ed.). London: Vintage Books.

FOUCAULT, Michel (1988). A Vontade de Saber. História da Sexualidade 1. Rio de Janeiro: Graal.

FREEDMAN, Carl (2000). Critical Theory and Science Fiction. Hanover: Wesleyan University Press.

GERNSBACK, Hugo (1927). Amazing Stories. New York: WRNY. 2 (3).

GIBSON, William (2008). Neuromancer. São Paulo: Aleph.

LANDON, Brooks (2003). Science fiction after 1900: from the Steam Man to the Stars. New York: Routledge.

LE GUIN, Ursula Kroeber. (2008). A mão esquerda da escuridão. São Paulo: Aleph. PARRINDER, Patrick (1980). Science Fiction: Its criticism and teaching. London: Methuen.

PUENZO, Lucía (2007). XXY. Historias Cinematograficas Cinemania.

RUSS, Joanna (1995). Speculations: "The subjunctivity of Science Fiction". In To write like a woman: Essays in feminism and Science Fiction. Indiana: Indiana University Press.

SUVIN, Darko (1979). Metamorphoses of Science Fiction: On the poetics and history of a literary genre. New Haven: Yale University Press. 